\title{
Microestructure alterations of rotary files after multiple simulated operative procedures
}

\author{
Arlinda Luzi ${ }^{1}$, Leopoldo Forner ${ }^{2}$, Amelia Almenar ${ }^{3}$, Carmen Llena ${ }^{4}$ \\ ${ }^{1}$ Assistant professor at the postgraduate program in Endodontics. \\ ${ }^{2}$ Professor. Operative Denstristy \& Endodontics Unit. Co-Director of the postgraduate program in Endodontics \\ ${ }^{3} \mathrm{Co}$-Director of the postgraduate program in Endodontics. \\ ${ }^{4}$ Associate professor. Operative Dentistry \& Endodontics Unit. \\ Department of Stomatology. Universitat de València. Valencia (Spain)
}

Correspondence:

Clínica Odontològica

Universitat de València

C/ Gascó Oliag, 1

46010 Valencia (Spain).

Forner@uv.es

\author{
Luzi A, Forner L, Almenar A, Llena C. Microestructure alterations of \\ rotary files after multiple simulated operative procedures. Med Oral Patol \\ Oral Cir Bucal. 2010 Jul 1;15 (4):e658-62. \\ http://www.medicinaoral.com/medoralfree01/v15i4/medoralv15i4p658.pdf

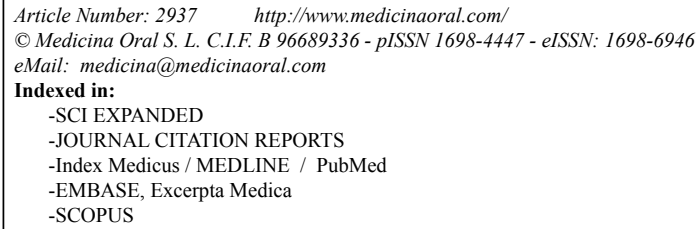

Received: 31/05/2009 Accepted: 28/11/2009

\begin{abstract}
Aim: To assess morphological alterations of ProTaper rotary NiTi files before and after continuous use by scanning electron microscopy (SEM).

Study Design: 30 root canals were chosen with an angle between 15 and $30^{\circ}$. Before starting to prepare the canals the files were observed microscopically using a scanning electronic microscope. The ProTaper sequence recommended by the manufacturer was used, with $\mathrm{NaOCl}$ as irrigant. The instruments were sterilised after every three canals were shaped. The instruments were observed with the same microscope after shaping each canal, until 30 root canals were shaped. The criteria used for checking the instruments were: blunt cutting edges, disruption of cutting edge, microfractures, fatigue cracks, metal flash, dentine remains.

Results: Many microscopic defects were found such as: cutting edge breaks (up to 70\%); fatigue cracks, between 33 and 100\%. No microfractures were found. An S1 and an SX file were fractured.

Conclusion: ProTaper instruments are quite reliable if used following usual requirements.
\end{abstract}

Key words: Endodontic files, endodontics, rotary endodontic instruments. 


\section{Introduction}

Nickel-Titanium NiTi endodontic instruments have made possible an enhanced quality of canal preparation and a reduction of working time $(1,2)$. The first study (3) about NiTi instruments showed that these files had two or three times more elastic flexibility and greater clockwise and anti-clockwise torsion fracture resistance than stainless steel files. The manufacture of NiTi instruments is much more difficult than the manufacture of stainless steel instruments because NiTi alloy is superelastic and cannot maintain the spirals because the alloy does not distort permanently. There are also many production difficulties, including the elimination of surface irregularities and metal flash on the cutting edges which can compromise the instruments cutting ability and would probably cause corrosion. New instruments present many imperfections, it is impossible to manufacture rotary instruments free of them (4). Although NiTi rotary files reduce the number of clinical mishaps, their use also implies an increased, but unpredictable incidence of file breakage. The fracture can occur with no preliminary visible defects so that the macroscopic inspection of these instruments is not a reliable method. The NiTi rotary file can be used between up to 10 (5) times, even though other authors (6) are unable to establish a number of uses.

The purpose of this study was to assess morphological alterations of ProTaper rotary NiTi files before and after continuous use by scanning electron microscopy (SEM).

\section{Materials and Methods}

For this study, 20 maxillary and mandibular molars which had been extracted for periodontal reasons were selected. Buccal-lingual and mesio-distal radiographs were obtained for all the teeth. 30 canals were chosen: mesial in the mandibular molars and mesial and distal in the maxillary molars. The canals were narrow with a single not very pronounced curve (angle between 15 and $30^{\circ}$ and a 4 to $5 \mathrm{~mm}$ radius). The radius and the angle of the curve were determined using Pruett's technique (7). Teeth were kept in a $0.1 \%$ thymol solution. The instruments used were ProTaper (Dentsply/Maillefer, Ballagigues, Switzerland) drived by an X-Smart motor (Dentsply/Maillefer, Ballagigues, Switzerland) at 250 rpm. Canals were prepared by one experienced operator. Before starting to prepare the canals, all the files were metalized with gold-palladium dust and were observed with a scanning electron microscope (S-2500, Hitachi, Ltd., Tokyo, Japan). All the files were photographed at different magnifications at $20 \mathrm{kV}$ and 180,270 and $360^{\circ}$ from lateral perspectives. Before the canals were prepared, the layer of gold was taken off from surface of the instruments using gauze and 40\% alcohol and then they were cleaned in an ultrasound bath. In all the teeth the pulp chamber was opened with a round drill, canals were irrigated with $1 \%$ sodium hypochlorite $(\mathrm{NaOCl})$ and negotiated with a $10 \mathrm{~K}$ file (Dentsply/Maillefer, Ballagigues, Switzerland). The working length was recorded $1 \mathrm{~mm}$ less when the file tip just emerged through the canal apical foramen. The work length was achieved with a $15 \mathrm{~K}$ file. The ProTaper sequence used, with the crown-down technique, was: crown preparation, S1, SX file until resistance is met, exiting from the canal with brush working motion; preparation of the middle third: S1 and S2 files until the working length with brush working motion; apex preparation: F1, F2 and F3 with continuous movement, only once, to the working length. There was abundant irrigation with $\mathrm{NaOCl}$ during preparation (after using each file). After use on three canals the instruments were cleaned first in an ultrasonic bath (U1trasonic Cleaning Sysytem 2014 -L\&R Manufacturing Company, New Jersey, USA-, with Biosonic -ColtèneWaledent-, Cuyahoga FalK, USA- for 5 minuts) and then were sterilised in an autoclave at $134^{\circ}$ for $60 \mathrm{~min}$ Miniclave 21ED (Matachana, Barcelona-Spain-). This procedure continued until 30 canals were prepared. Fractured files were replaced by others which were previously examined under the same microscope. After using the ProTaper sequence in one canal, the instruments were dried, observed macroscopically with $2 x$ magnification and then metalized with gold-palladium dust and observed microscopically. Each of the instruments was photographed in the same position to see the wear and tear and compare its aspect with new instruments. This procedure was repeated with each instrument until 30 canals had been prepared with each instrument. The criteria used for checking the instruments were: visible defects, microscopic defects like: blunt cutting edges, disruption of the cutting edge, microfractures, fatigue cracks, metal flash, complete fractures, manufacturing defects, pitting and dentine smear debris. Percentage of disruptions and cracks were calculated.

\section{Results}

The initial observations of the new instruments are summarised in table 1.

Although no macroscopic defects were found, many microscopic defects were observed after using ProTaper instruments (Fig. 1), such as: cutting edge disruptions from 0 to $70 \%$ or fatigue cracks between 33 and $100 \%$ (Table 2).

No microfractures in the instruments were found in this study. All surface cracks found were prolongations of fatigue cracks. Metal remains were found on all instruments and they were on the cutting edges of the files. Nicks on the cutting edges were observed in all the instruments before and after use. In this study only 2 of the 8 instruments used were fractured, that is $25 \%$ of the instruments or $6.7 \%$ of the prepared canals. An 
S1 and an SX file were fractured. The S1 instrument fractured (Fig. 2) with no prior visible distortion on the sixth canal (6th use) and the SX instrument also fractured with no prior visible distortion on the 20th canal (20th use).

Dentine smear debris were found on all the instruments after use (Fig. 3). Furthermore, dentine smear debris were found even after the instruments had been in an ultrasound bath and sterilised in autoclave. Embedded dentin chips were found in fatigue cracks. Pitting was found in F2, SX, S2. SX (1) in canal no. 7, F2 in canal no. 10 and $\mathrm{S} 2$ in canal no. 22 .

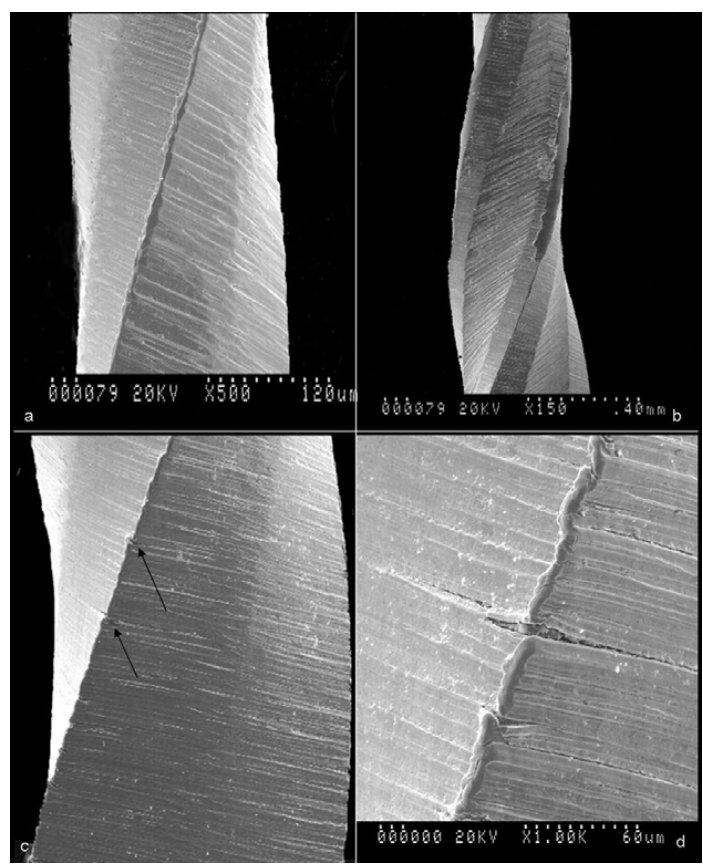

Fig 1. Alterations in Protaper instruments: a) Blunt cutting edge in a new SX Protaper file; b) cutting edge disruption in an F3 ProTaper file after 10 shaped canals; c) fatigue crack in S1 ProTaper file; d) detail of a crack in a F3 instrument.

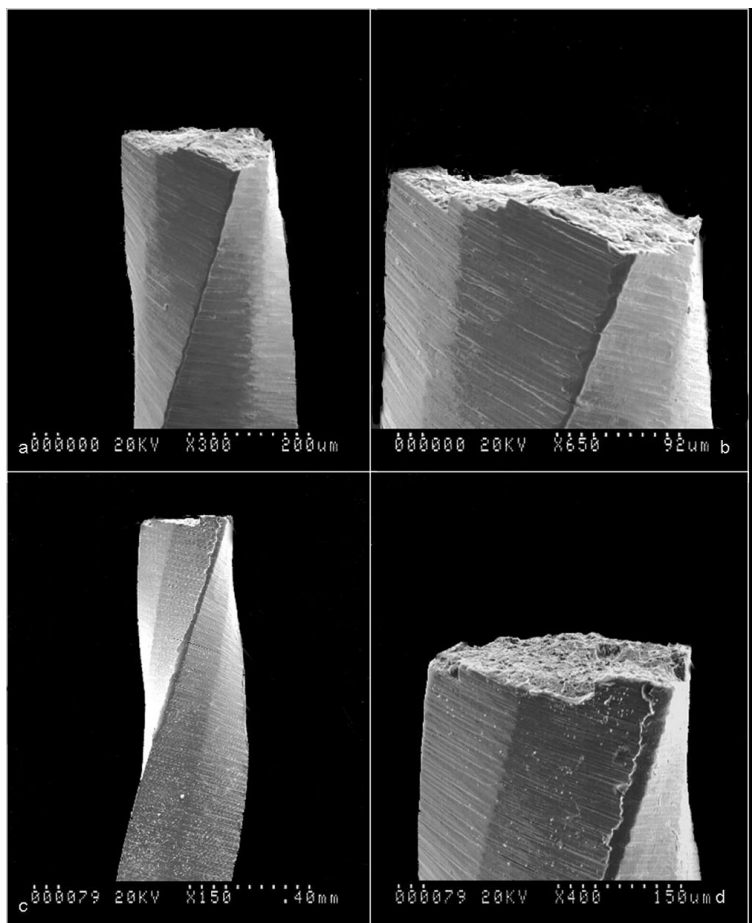

Fig 2. Instrument fracture: $a-b)$ fracture in a SX ProTaper instrument after 21 shaped Canals; c-d) fracture in a S1 ProTaper instrument appeared in the 6th canal.

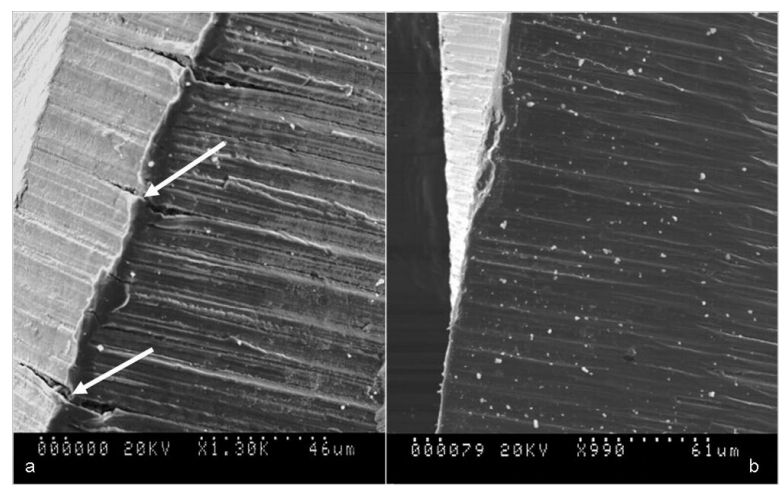

Fig 3. Alterations in ProTaper instruments: a) Dentin smear debris inside the cracks in a F3 ProTaper instrument in the 20th canal; b) Blunt cutting edge in a SX ProTaper file after 7 shaped canals.

Table 1. Heading: Initial alterations of instruments before being used.

\begin{tabular}{|l|l|l|l|l|l|l|l|l|}
\hline & SX(1) & SX(2) & S1(1) & S1(2) & S2 & F1 & F2 & F3 \\
\hline Disruption of cutting edge & No & No & No & No & No & No & No & No \\
\hline Fracture & No & No & No & No & No & No & No & No \\
\hline Microfracture of the surface & No & No & No & No & No & No & No & No \\
\hline Dentine smear debris & No & No & No & No & No & No & No & No \\
\hline Blunt cutting edges & Yes & Yes & Yes & Yes & Yes & Yes & Yes & Yes \\
\hline Manufacturing defects & Yes & Yes & Yes & Yes & Yes & Yes & Yes & Yes \\
\hline Macroscopic defects & No & No & No & No & No & No & No & No \\
\hline Fatigue cracks & No & No & No & No & No & No & No & No \\
\hline
\end{tabular}

Foot note: (1) and (2): different SX and S1 files used. 
Table 2. Heading: Number and percentage of disruption of cutting edges and percentage of fatigue cracks observed after using ProTaper instruments.

\begin{tabular}{|c|c|c|c|c|c|}
\hline Files & $\begin{array}{c}\text { Prepared } \\
\text { canals }\end{array}$ & \multicolumn{2}{|c|}{$\begin{array}{c}\text { Number and percentage of pre- } \\
\text { pared canals when observed } \\
\text { disruption of cuttingg edges }\end{array}$} & \multicolumn{2}{|c|}{$\begin{array}{c}\text { Number and percentage of } \\
\text { prepared canals when } \\
\text { observed fatigue cracks }\end{array}$} \\
\hline SX(1) & 21 & 0 & $0 \%$ & 19 & $90 \%$ \\
\hline SX(2) & 9 & 0 & $0 \%$ & 3 & $33 \%$ \\
\hline S1(1) & 5 & 0 & $0 \%$ & 5 & $100 \%$ \\
\hline S1(2) & 25 & 0 & $0 \%$ & 22 & $88 \%$ \\
\hline S2 & 30 & 12 & $40 \%$ & 27 & $90 \%$ \\
\hline F1 & 30 & 12 & $40 \%$ & 27 & $90 \%$ \\
\hline F2 & 30 & 12 & $40 \%$ & 27 & $90 \%$ \\
\hline F3 & 30 & 21 & $70 \%$ & 25 & $83,3 \%$ \\
\hline
\end{tabular}

Foot note: (1) and (2): different SX and S1 files used.

\section{Discussion}

Other authors have described alterations in endodontic instruments: LightSpeed instruments were studied (4) before and after use in an indeterminate number of canals; Quantec instruments (8) were studied after they had been used an unspecified number of times (9). In our study, the instruments were examined before and after working with them on each canal. Thus, it has been possible to see when alterations start to appear on the files and what type of changes are found after each use. This study used the same SEM magnifications used by other authors (3). The same speed was used for all the instruments and all the teeth were prepared by the same operator. The instruments were cleaned with $40^{\circ}$ alcohol because it does not alter the composition of $\mathrm{NiTi}$ instruments $(4,6)$. As reported by Eggert et al. (4), this study also found alterations in all the new instruments. Other authors, also found defects in new instruments; the most frequently found alterations were metal strips and blunt cutting edges; after one use, the instruments showed alterations such as fatigue cracks (6). In our study this alteration was only found in S1.

No macroscopic defects were found as in GT files (10) in contrast to other studies (6) where two visible distortions appeared using Profile rotary system, or where only one instrument out of 121 ProTaper instruments was found (11) ; and the one by Ounsi et al. (12), who described three instruments with macroscopic deformations in 80 ProTaper original system sets. Sattapan et al. (9) found that $50 \%$ of instruments showed visible defects but this study provides no information on the number of canals on which the files were used. Other recent study (5) also reports visible defects in Mtwo rotary instruments. This may be due to methodology because the above studies were clinical, although some authors (4) found no visible defects in a clinical study.
Rapisarda et al. (13) observed fatigue crack after the files had worked for 60 seconds on the canal, Peng et al. (11) and Wei et al. (14) found wear and tear fissures in ProTaper instruments. In our work we detected fatigue cracks in all the instruments observed. S1(1) instrument presented fatigue crack after the first use, although the other instruments showed the same imperfection after 2 until 6 uses.

Any instrument analyzed in our work presented microfractures (fractures of the surface of the instrument not of the cutting edges), fact that contradict the findings by other authors as Eggert et al. (4), that found some microfractures in Lightspeed instruments or Rapisarda et al. (13), who found microfractures on all instruments after $60 \mathrm{~s}$. of work, but in this last case shaping was done in endodontic training models and the speed used was 340 rpm. Viera et al. (15) found transversal microcracks on ProTaper instrument cutting edges after using them on 5 or 8 molars, probably associated to the forces the instruments are subject to at the curved part of the canals that are similar of fatigue cracks founds in this study.

Metal flash were present on all files, and were also found by Eggert et al. (4), who reported $0 \%$ to $18.8 \%$ in used instruments, in this last case the decreasing percentage is explained by the wear on the files after working on the canals. Wei et al. (14) found metal flash on ProTaper instruments. The present study found an increase in metal flash on new and used instruments.

Blunt cutting edges were also observed in this present study on all new and used files, as reported by Eggert et al. (4), who also found them on new and used instruments.

After a full clean with ultrasound bath and a sterilisation technique, on all ProTaper files, dentine remnants were found on the cutting edges, they were also found trapped in fatigue cracks as described by other authors (11). Sterilization of previously used files is not $100 \%$ 
effective (16), so the presence of micro defects on the files surface could improve debris retention and a probable increase of the cross infection risk.

The sterilization process and material fatigue due to the repeated usage are two important factors affecting files microstructure. Sterilization with dry heat (11 cycles) is able to produce a significant increment of the superficial roughness in nickel-titanium instruments, leading to an improve of the debris retention capability (17). Other authors have shown that wet heat (with 10 cycles as in our study), produced nanostructural superficial changes in nickel-titanium endodontic files (18).

In our work only two instruments experiment fracture. The S1 file after preparing 6 canals and the SX file after 22 . The number of separated files was $25 \%$ according to the number of files used (7\% according to the canals prepared). All the instruments that experiment fracture showed a sharp break without any accompanying visible defects. In the S1 file the SEM photomicrographs showed that fatigue cracks in this file were present after the first use. The fractures found in this present work were due to fatigue, this type of fracture in ProTaper ins-truments has also been described by SpanakiVoreadi et al. (19), Peng et al. (11) and Wei et al. (14), although the latter also found torsion fractures. Peng et al. (11) reported a similar fracture percentage $(24.6 \%)$ to the one observed here in S1 files. In the present study, the percentage of separated files is $25 \%$ as there were only 8 used files because the study aimed was to check wear on files after use, but the S2, F1, F2, and F3 files prepared 30 canals without fracturing. Fife et al. (20) did not separate any ProTaper instruments but they were used only on 4 molars; only 3 instruments, S1 and 4S2 were distorted in contrast to the F1, F2 and F3 instruments. The authors explain this by the fact that the $\mathrm{S}$ files wide and shape the canal so the clinical behaviour of $\mathrm{F}$ instruments is more foreseeable and constant.

Different types of defects are found on ProTaper files, from small imperfections to blunt and even disruption on the cutting edges. Fatigue cracks were found on all instruments, which suggest that the nature of these imperfections is through flexural fatigue in most cases and due to torsion in a minority of cases. We can affirm that using low magnification is impossible to observe defects in ProTaper rotary NiTi files. The lowest magnification used in this study that allow us to observe an imperfection was 50X in en F3 file after shaping six root canals.

\section{Conclusion}

Under the study conditions, it can be concluded that ProTaper instruments may be used more than once, despite the number of alterations to the files. It seems that even the smallest instrument can be used multiple times without fear of fracture.

\section{References}

1. Peters OA. Current challenges and concepts in the preparation of root canal systems: a review. J Endod. 2004;30:559-67.

2. Martín-Micó M, Forner-Navarro L, Almenar-García A. Modification of the working length after rotary instrumentation: a comparative study of four systems. Med Oral Patol Oral Cir Bucal. 2009;14:E153-7.

3. Walia HM, Brantley WA, Gerstein H. An initial investigation of the bending and torsional properties of Nitinol root canal files. J Endod. 1988; 14:346-51.

4. Eggert C, Peters O, Barbakow F. Wear of nickel-titanium lightspeed instruments evaluated by scanning electron microscopy. J Endod. 1999;25:494-7.

5. Plotino G, Grande NM, Sorci E, Malagnino VA, Somma F. A comparison of cyclic fatigue between used and new Mtwo Ni-Ti rotary instruments. Int Endod J. 2006;39:716-23.

6. Svec TA, Powers JM. The deterioration of rotary nickel-titanium files under controlled conditions. J Endod. 2002;28:105-7.

7. Pruett JP, Clement DJ, Carnes DL Jr. Cyclic fatigue testing of nickel-titanium endodontic instruments. J Endod. 1997;23:77-85.

8. Hervás García A, Forner Navarro L, Llena Puy MC, Zaragoza Cardells E. Cutting efficiency evaluation of Quantec Series 2000 orifice openers with computed tomography (CT). Med Oral Patol Oral Cir Bucal. 2008;13:E516-22.

9. Sattapan B, Nervo GJ, Palamara JE, Messer HH. Defects in rotary nickel-titanium files after clinical use. J Endod. 2000;26:161-5.

10. Tripi TR, Bonaccorso A, Tripi V, Condorelli GG, Rapisarda E. Defects in GT rotary instruments after use: an SEM study. J Endod. 2001;27:782-5.

11. Peng B, Shen Y, Cheung GS, Xia TJ. Defects in ProTaper S1 instruments after clinical use: longitudinal examination. Int Endod J. 2005;38:550-7.

12. Ounsi HF, Salameh Z, Al-Shalan T, Ferrari M, Grandini S, Pashley $\mathrm{DH}$, et al. Effect of clinical use on the cyclic fatigue resistance of ProTaper nickel-titanium rotary instruments. J Endod. 2007;33:73741.

13. Rapisarda E, Bonaccorso A, Tripi TR, Condorelli GG, Torrisi L. Wear of nickel-titanium endodontic instruments evaluated by scanning electron microscopy: effect of ion implantation. J Endod. 2001;27:588-92.

14. Wei X, Ling J, Jiang J, Huang X, Liu L. Modes of failure of ProTaper nickel-titanium rotary instruments after clinical use. J Endod. 2007;33:276-9.

15. Vieira EP, França EC, Martins RC, Buono VT, Bahia MG. Influence of multiple clinical use on fatigue resistance of ProTaper rotary nickel-titanium instruments. Int Endod J. 2008;41:163-72.

16. Morrison A, Conrod S. Dental burs and endodontic files: are routine sterilization procedures effective? J Can Dent Assoc. 2009;75:39.

17. Alexandrou G, Chrissafis K, Vasiliadis L, Pavlidou E, Polychroniadis EK. Effect of heat sterilization on surface characteristics and microstructure of Mani NRT rotary nickel-titanium instruments. Int Endod J. 2006;39:770-8.

18. Valois CR, Silva LP, Azevedo RB. Multiple autoclave cycles affect the surface of rotary nickel-titanium files: an atomic force microscopy study. J Endod. 2008;34:859-62.

19. Spanaki-Voreadi AP, Kerezoudis NP, Zinelis S. Failure mechanism of ProTaper Ni-Ti rotary instruments during clinical use: fractographic analysis. Int Endod J. 2006;39:171-8.

20. Fife D, Gambarini G, Britto Lr L. Cyclic fatigue testing of ProTaper NiTi rotary instruments after clinical use. Oral Surg Oral Med Oral Pathol Oral Radiol Endod. 2004;97:251-6. 